It seems to me that the question of leave for patients who are detained under the Mental Health Act, even those who are restricted, is a question for clinical judgement and that a blanket restriction from the Secretary of State is inappropriate. It also serves to detract from the notion that a Hospital Order is for treatment rather than punishment.

I think there is a very real question about whether psychiatrists should agree to be bound by a directive of this nature, especially since it raises the possibility of future directives of a more restrictive nature.

E. C. CROUCH, Mental Health Services Directorate, South Buckinghamshire NHS Trust, Amersham General Hospital, Amersham HP7 OJD

\section{Seclusion of control and restraint?}

Sir: The Code of Practice (HMSO) states that "seclusion is a last resort". "its sole aim ... is to contain severely disturbed behaviour which is likely to cause harm to others". Upon seclusion it recommends that a doctor attend "immediately". If seclusion continues, it requires documented reports every 15 minutes, two nurses reviewing the patient every two hours, and a doctor reviewing every four hours. Prolonged seclusion requires a senior doctor, nurses, and other professionals to review the case. Detailed clinical notes and separate seclusion records must be kept while managers are required to monitor the use of seclusion. However, advice on other forms of restraint is less detailed. Although the code requires a "senior officer" to be informed of restraint lasting over two hours it does not require involvement of medical staff, the keeping of specific records, or frequent reviews of the need for continued restraint.

'Control and restraint' (C \& R) is a widely used form of restraint. It derives from the martial art aikido where manipulation of the joints is used to provide 'locks' which restrain the violent patient. C \& $R$ is performed by specially trained nursing staff who operate in teams of three or more. It is an effective way to restrain a violent patient in the short term but is not without its drawbacks. It involves considerable invasion of the patient's 'personal space' and an almost total restriction of movement. A patient who struggles while in C \& $R$ 'locks' experiences considerable pain in the wrists and other joints. Physical injuries such as bruising, sprains and 'carpet burns' have occurred.

In some psychiatric units prolonged $C \& R$ is used in circumstances where seclusion would previously have taken place. This arises either because $C \& R$ is felt to be preferable, or because a seclusion room is no longer available. It is my concern that prolonged or repeated use of $C \& R$ is a potential abuse of the patient, but is not always subject to the same strict monitoring as seclusion. Prolonged or frequent $\mathbf{C} \& \mathrm{R}$ deserves similar monitoring procedures to those used with seclusion. The code implies that seclusion is more extreme than other forms of restraint like $C \& R$, but at times the reverse is true. Increased use of prolonged or frequent C \& R should be viewed with caution.

DePartment OF Health and Welsh OfFice (1993) Code of Practice. Mental Health Act 1983, London: HMSO. Pp 74-85.

J. D. D. LAIDLAW, Queen Elizabeth Psychiatric Hospital, Birmingham B15 2QZ

\section{Is this an article too far?}

Sir: There is a series in the Psychiatric Bulletin whose place remains a mystery to me. When I first read Dr Culliford's 'Wisdom' articles, I requested him to explain what 'wisdom' was (Azuonye, 1992), but he was unable to do so, "It is difficult to be definitive on the question of what wisdom is" (Culliford, 1992). Without demonstrating that he possesses a clear notion of what 'wisdom' means to him, he has continued to write about it.

The latest 'Wisdom' article (Culliford, 1994) is one of the worst pleces I have come across in a scientific journal. Taking the surprising view that emotions are "... pleasing (positive) [or] noxious (negative) ...", he states that a person who is not sad is happy, one who is not anxious is calm, one who does not feel guilty is in a state of pure-minded innocence; and, most staggeringly, that a person who is not feeling angry is in a state of Wisdom! He fails to recognise that human emotions are expressed on a spectrum, and that there exists an 'all right' feeling, neither sadness nor happiness, which is the normal emotional state of most of us.

The compassionate understanding which is the essence of psychiatry is a religious phenomenon. Contributions which possess a religious or philosophical content therefore have a place in a journal of trends in 
psychiatric practice. But I wonder, whether Dr Culliford's 'Wisdom' articles, which offer a very superficial and simplistic picture of the nature of things, may not do serious harm to the viewpoints of readers who believe that their publication in the Psychiatric Bulletin implies that these articles possess merit or value.

AzUONYE, I. O. (1992) Wisdom. Psychiatric Bulletin, 16, 174 CULUFORD, L. (1992) Wisdom (Response to Azuonye). Psychiatric Bulletin, 16, 174.

- (1994) Wisdom for Psychiatrists: The wisdom of nonanger. Psychiatric Bulletin, 18, 709.

IKECHUKWU O. AZUONYE, Forest Healthcare NHS Trust, Claybury Hospital, Manor Road, Woodford Bridge, Essex IG8 8BY

Sir: How does one explain the ineffable?

Wisdom can be compared, for example, to poetry. One need not be able to define poetry to compose or even to write about it.

The pieces, those published so far and those to come, are offerings, just that, with benevolent intent. I have no axes to grind. They are perhaps there simply as starting points for reflection. Each recipient of the Bulletin has choices to make: whether to read in the first place, whether (having read) to allow only an immediate reaction, or whether to reflect more deeply. In this way, each will be able to decide for her or himself whether such a piece is of any value-curiosity value, entertainment value, even (and only lastly, I would say) of any instructional value.
There is no shame in offering choices. Tastes and inclinations vary. Your correspondent has made his clear. I am sorry to have caused offence to him or any other reader and offer my apologies.

It does seem possible, however, that $\mathrm{Dr}$ Azuonye may have over-estimated the toxic potential of this series of short articles on Wisdom (Poetry?) for Psychiatrists. Your readers are all well-educated people, each safely to be credited with a good measure of discernment. It is not really for me to comment on editorial decision-makdng, nevertheless that you may agree with me on this point seems likely. I am simply grateful that you have continued to accept my contributions. It barely seems necessary to add that I have always had complete confidence in your judgement.

I have no quarrel with Dr A (or with anybody else) on these matters. I suspect that were he and I to meet and have a conversation, we would quickly discover between our philosophies an enormous amount of common ground, particularly in terms of advisable precepts (instructions regarding conduct). We would share for example, I feel sure, the ideal of what might be called neighbourliness; embodying as it does attitudes of patience, tolerance, kindness and courtesy. I believe it quite likely that we would in time become friends.

LARRY CULLIFORD, South Downs Health NHS Trust, Hove Community Mental Health Centre, 35 New Church Road, Hove BN3 4AG 